\title{
Prognostic factors for overall survival in patients with spinal metastasis secondary to prostate cancer: a systematic review and meta-analysis
}

Zhong-yu Gao ${ }^{1}$, Tao Zhang ${ }^{1}$, Hui Zhang ${ }^{1}$, Cheng-gang Pang ${ }^{2}$ and Wen-xue Jiang ${ }^{1 *}$

\begin{abstract}
Background: To guide the selection of treatments for spinal metastases, the expected survival time is one of the most important determinants. Few scoring systems are fully applicable for spinal metastasis secondary to prostate cancer (PCa). This study aimed to identify the independent factors to predict the overall survival (OS) of patients with spinal metastases from PCa.
\end{abstract}

Methods: The PubMed, Embase and CENTRAL were retrieved by two reviewers independently, to identify studies analyzed the prognostic effect of different factors in spinal metastasis from PCa. A systematic review and quantitative meta-analysis was conducted with hazard ratio (HR) and $95 \%$ confidence interval $(95 \% \mathrm{Cl})$ as the effect size.

Results: A total of 12 retrospective cohort studies (1566 patients) were eligible for qualitative synthesis and 10 for quantitative meta-analyses. The OS was significantly influenced by performance status, visceral metastasis, ambulatory status and time from PCa diagnosis in more than half of the available studies. The meta-analyses demonstrated that OS was significantly influenced by visceral metastasis ( $\mathrm{HR}=2.24,95 \% \mathrm{Cl}: 1.53-3.27, p<0.001)$, pretreatment ambulatory status ( $\mathrm{HR}=2.64,95 \% \mathrm{Cl}: 1.82-3.83, p<0.001)$, KPS ( $\mathrm{HR}=4.45,95 \% \mathrm{Cl}: 2.01-9.85, p<0.001)$, ECOG $(\mathrm{HR}=2.96,95 \% \mathrm{Cl}: 2.02-4.35, p<0.001)$, extraspinal bone metastasis $(\mathrm{HR}=2.04,95 \% \mathrm{Cl}: 1.13-3.68, p=0.018)$, time developing motor deficit $(\mathrm{HR}=1.57,95 \% \mathrm{Cl}: 1.30-1.88, p<0.001)$ and time from PCa diagnosis $(\mathrm{HR}=1.37,95 \% \mathrm{Cl}: 1.17-$ $1.59, p<0.001)$.

Conclusions: Visceral metastasis, ambulatory status, extraspinal bone metastasis, performance status, time developing motor deficit and time interval from primary tumor diagnosis were significantly associated with the OS for spinal metastasis from PCa. When selecting the treatment modality, clinicians should fully consider the patients' systematic status based on all potential prognostic factors.

Level of evidence: I Meta-analysis.

Keywords: Spinal metastasis, Prognostic factors, Meta-analysis, Prostate cancer

\footnotetext{
* Correspondence: 3492113325@qq.com

'Department of Orthopedic Surgery, Tianjin First Central Hospital, 24 Fukang

Rd, Nankai District, Tianjin 300192, China

Full list of author information is available at the end of the article
}

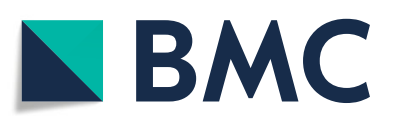

() The Author(s). 2020 Open Access This article is licensed under a Creative Commons Attribution 4.0 International License, which permits use, sharing, adaptation, distribution and reproduction in any medium or format, as long as you give appropriate credit to the original author(s) and the source, provide a link to the Creative Commons licence, and indicate if changes were made. The images or other third party material in this article are included in the article's Creative Commons licence, unless indicated otherwise in a credit line to the material. If material is not included in the article's Creative Commons licence and your intended use is not permitted by statutory regulation or exceeds the permitted use, you will need to obtain permission directly from the copyright holder. To view a copy of this licence, visit http://creativecommons.org/licenses/by/4.0/ The Creative Commons Public Domain Dedication waiver (http://creativecommons.org/publicdomain/zero/1.0/) applies to the data made available in this article, unless otherwise stated in a credit line to the data. 


\section{Background}

Prostate cancer $(\mathrm{PCa})$ is the most frequent malignant tumor and the second leading cause of cancer-related death in men from many developed countries [1]. PCa is generally sensitive to androgen blockade and chemotherapy, which can be divided into hormone-refractory type and hormone-naive type according to the response to hormone therapy. Though the prognosis of $\mathrm{PCa}$ is much better than that of many other malignant tumors such as lung cancer or gastrointestinal cancer, 80 to $100 \%$ of patients with advanced PCa develop bone metastases, of which the spine is the most common site of bone metastases $[2,3]$. When spinal metastases occur, about onethird of patients will have symptoms, including pathological fractures, metastatic spinal cord compression (MSCC), and pain, which often severely impairs patients' overall survival and quality of life $[4,5]$.

Many therapeutic modalities could be applied for patients with metastatic spinal disease from PCa. Generally, surgical intervention is required for vertebral compression fractures, vertebral segment instability, intractable pain and progressive neurological deficits, paraplegia, or quadriplegia [6, 7]. Unlike spinal metastases from some other cancers, such as renal cell carcinoma and malignant melanoma, metastatic spinal tumor from PCa are often more sensitive to radiation therapy (RT) $[8,9]$. Thus, mild MSCC is also sensitive to external radiation therapy. In additional, for most newly diagnosed cases of spinal metastases from PCa, castration by reducing testosterone level though surgery or medication also has a significant effect on the relief of bone pain symptoms.

In the selection of treatment options for patients with spinal metastases, the patient's expected survival time is one of the most important determinants. At present, in order to more accurately predict the survival time of patients and guide clinical treatment, many corresponding scoring systems have been proposed, including Tokuhashi [10], Tomita [11], Van der Linden [12], Bauer [13], and so on. These scoring systems contain some important prognostic factors that predict overall survival, such as patients' performance status, number of extra-spinal or spinal bone metastases, visceral metastases, primary tumor type, and pathological fractures. However, the prognostic factors used in these scoring systems are not completely consistent, given contradictory survival expectations of specific patients based on different scoring systems. In addition, few scoring systems are fully applicable to specific primary tumor types. Several retrospective cohort studies have identified some potentially significant predictors for overall survival in patients with spinal metastasis from PCa [14-16]. However, these studies were conducted based on small samples, and different factors were included for analysis. Therefore, the purpose of this study is to identify the independent factors to predict the overall survival of patients with spinal metastases from PCa.

\section{Methods}

\section{Data source and studies retrieval}

This review was conducted according to the guidelines outlined in Preferred Reporting Items for Systematic Reviews and Meta-analysis (PRISMA) statement [17]. Two individual reviewers retrieved the platforms of PubMed, Embase and CENTRAL, from the inception to October 2019. The key words used for searching include "spinal metastasis", "prostate cancer", "overall survival" and "prognostic factor". In additional, the reference lists of the included studies were screened and potentially related studies were hand-searched for possible inclusion.

\section{Inclusion and exclusion criteria}

All retrieved records were screened for final inclusion based on the following inclusion criteria: (1) patients diagnosed as spinal metastasis from PCa; (2) studies associated with evaluating the prognostic effect of predict factors of overall survival; (3) studies designed as observational clinical study, including cohort studies and case-control studies would be eligible for inclusion. Studies would be excluded based on the following criteria: (1) duplicated studies; (2) animal studies, literature review, commentary studies and meta-analyses; (3) studies used the same cohort.

\section{Study selection and data extraction}

After excluding the duplicates, the remained records were screened with their titles /abstracts according to the inclusion criteria. Then, the potentially related titles /abstracts were further assessed for the final inclusion using their full texts.

Two authors independently extracted the following data from included studies:

(1) Study characteristics: lead author, publication year, lead author's country, study design and study period;

(2) Patients information: numbers of involved patients and patients with MSCC, median age, pre- and post-treatment neurological status, performance status, visceral metastasis, extraspinal bone metastasis, number of involved vertebrae, distribution of involved vertebrae, prostate-specific antigen (PSA), Gleason grade of $\mathrm{PCa}$, and hormonal status (hormone-refractory or hormone-naive $\mathrm{PCa}$ );

(3) Treatment modalities: treatment of primary PCa, major treatment to spinal lesions, adjuvant therapies prior to and after major treatment, 
indication for surgery, re-operation and complications.

(4) Outcomes information: overall survival and the associated prognostic factors.

We determined the cause of diversity in obtained information and resolved disagreement through discussion.

\section{Quality assessment of included studies}

Two reviewers performed the process of quality assessment independently using the Newcastle-Ottawa Scale (NOS) [18]. This scale employs a 9 stars system that assesses three domains: patient selection, comparability of study groups and ascertainment of study outcome. Studies with a score of less than 6 indicates a high chance of bias.

\section{Quantitative data analysis}

As the prognostic effects of the factors were represented with hazard ratio (HR) and 95\% confidence interval $(95 \% \mathrm{CI})$ in the primary studies, meta-analysis was performed using HR as effect size. In case with significant heterogeneity $\left(\mathrm{I}^{2}>50 \%\right.$, or $p<0.1$ by $\mathrm{Q}$ test), randomeffect model would be employed, while fixed-effect model was selected when no significant heterogeneity exists [19]. $Z$ test was used to test the significance of the pooled effect size.

When five or more studies were included in a quantitative analysis, sensitivity analysis and publication bias test (Begg's and Egger's regression asymmetry test, $p<0.050$ and $p<0.100$ were considered to be with significant publication bias respectively) would be conducted [20].

The statistical procedures were conducted through software of Stata version 15.0 (StataCorp LLC, College Station, Texas, USA). The statistical significance was defined at a two-sided $p$ value of less than 0.05 .

\section{Results}

\section{Study searching and selecting}

The flowchart of the study searching and selecting is shown in Fig. 1. A total of 861 records were screened in the initial searching. After excluding of 158 duplicates, 703 titles /abstracts were assessed for potential eligibility. Then, 35 full-text articles were further screened, remaining 12 eligible studies [14-16, 21-29] for qualitative synthesis and 10 eligible studies [14-16, 22, 23, 2529] for quantitative meta-analysis finally.

\section{Characteristics of the included studies}

The summary of the included studies is available in Table 1. A total of 1566 patients were retrospectively included in these cohort studies, among which 1189 patients were proven to be with MSCC. The median ages ranged from 65 to 77 years among the included cohorts.
The prevalence of visceral metastasis and extraspinal bone metastasis was available in nine [14-16, 22-25, 27, 29] and eight studies [15, 16, 22-25, 27, 28] respectively, with incidences of $26.7 \%$ (355 of 1329 patients) and 69.6\% (864 of 1242 patients). The number of involved vertebrae was reported in seven studies [21, 23, 24, 26-29], giving 490 (46.1\%) patients with 1-2 spinal lesions and 572 (53.9\%) patients with 3 or more than 3 spinal lesions. The median overall survival was presented in eight studies with a range of 444 months. The overall survival rates at different follow-up periods are shown in Fig. 2a. The survival rates at 1, 3, 6, 12, 24 and 60 months after treatment were $90.6 \%$ (135/149 patients), $71.6 \%$ (161/225 patients), 56.9\% (568/999 patients), $51.8 \%$ (691/1334 patients), $34.2 \%$ (66/193 patients) and $19.7 \%$ (6/29 patients) respectively. Figure $2 b$ shows the percentages of ambulatory and non-ambulatory patients at different time points. Among the alive patients, the percentage of the ambulatory patients continues to increase.

The therapeutic modality performed in each study is displayed in Table 2. Various treatments to the primary PCa were performed, mainly including prostatectomy, hormone therapy (either orchiectomy or treatment with gonadotropin-releasing hormone agonists), radiation therapy and chemotherapy. Regarding the major treatment, five studies were performed with various decompression surgeries with or without instrumentation procedures. Various radiation courses were applied in four studies without operative procedures, while both surgical treatment and radiotherapy were applied in two studies. Different adjuvant therapies were applied before the major therapy, mainly including narcotics for pain management, steroids, radiation therapy and bisphophonates (BP). Following the major therapy, radiotherapy, BP, narcotics, steroids and chemotherapy were applied as adjuvant therapy. In the five studies [14-16, 22, 24] associated with operative procedures, post-operative complications were recorded in $37.4 \%$ (83 of 222) of the patients.

Generally, the included studies were of a favorable methodological quality by NOS. The mean NOS was $7.3 \pm 0.9$ stars, and no study has a NOS score of less than 6 .

\section{Results of qualitative synthesis}

As shown in Fig. 3, a total of 14 prognostic factors were assessed in at least two primary studies by either univariate or multivariate analysis. These factors include age at treatment, performance status (either Karnofsky performance score [KPS] or Eastern Cooperative Oncology Group-performance score [ECOG]), visceral metastasis, other bone metastasis, ambulatory status, PSA, time from the primary $\mathrm{PCa}$ diagnosis, spinal tumor location, Gleason grade, lymph metastasis, number of involved vertebrae, hormone status, BP treatment and the time developing motor deficit. The overall survival was significantly associated with performance status, visceral 


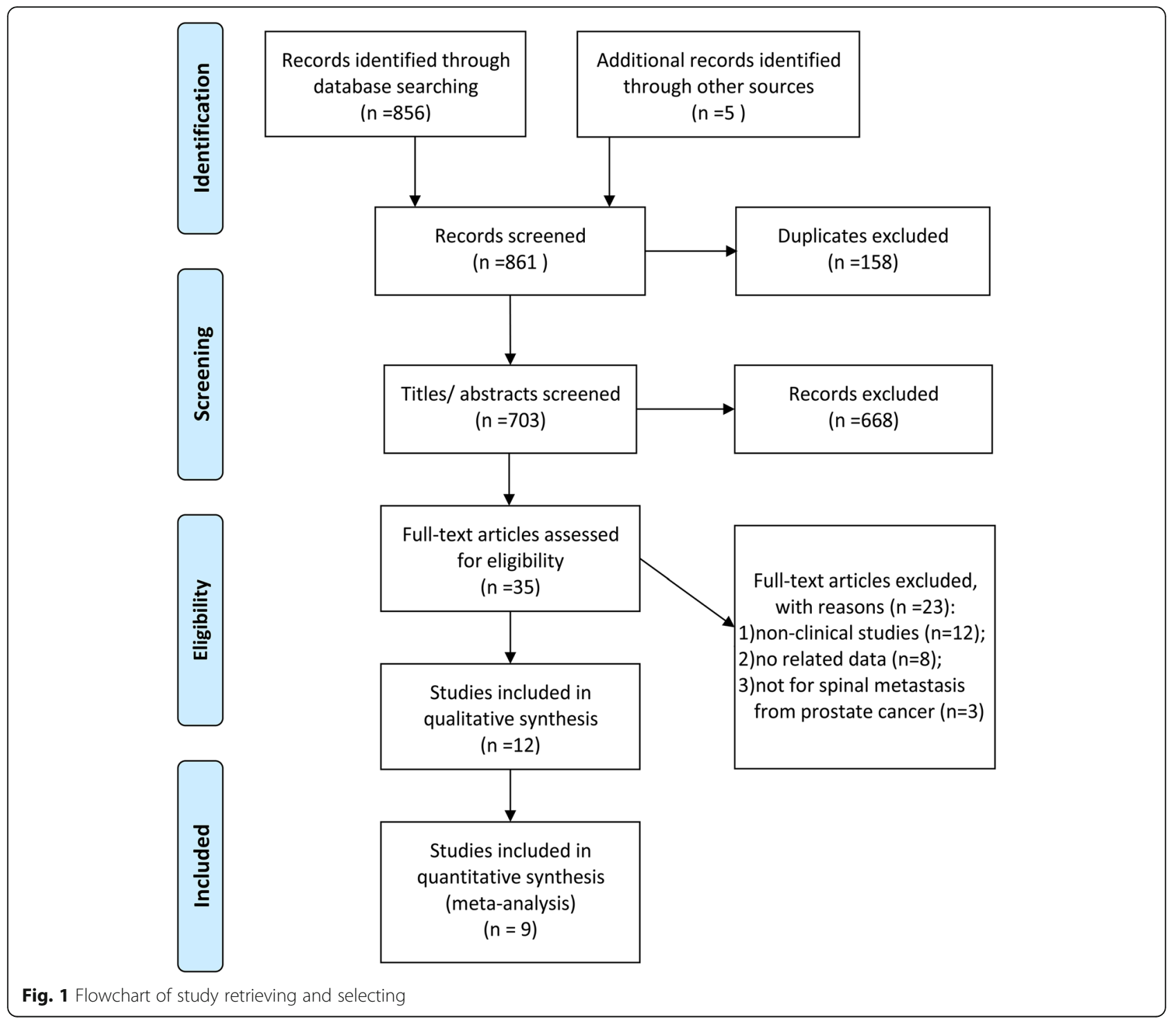

metastasis, ambulatory status and time from PCa diagnosis in more than half of the available studies.

Some other factors were additionally analyzed in only one of the studies, such as applying of preoperative RT to the spine, total doses of RT applied to the spinal lesions ( $\leq 30 \mathrm{~Gy}$ vs. $>30 \mathrm{~Gy}$ ), presence of major complications, surgical approach (anterior vs. non-anterior), previous prostatectomy, Crnalic prostate score, urinary and bowel continence, Tomita score, revised Tokuhashi score, previous hormone therapy, haemoglobin $(>12 \mathrm{~g} / \mathrm{L}$ vs. $\leq 12 \mathrm{~g} / \mathrm{L}$ ), postoperative ambulatory status, presence of MSCC, antiangiogenic drugs and psoas muscle measurements. Among these, Tomita score, previous hormonotherapy, haemoglobin, post-operative ambulatory status and psoas muscle measurements were presented to be significant prognostic factors of overall survival.

\section{Results of quantitative meta-analyses}

Figure $4 \mathrm{a}-\mathrm{h}$ show the forest plots of all available predictors of survival, demonstrating that overall survival was significantly influenced by visceral metastasis (present vs. absent, $\mathrm{HR}=2.24,95 \% \mathrm{CI}: 1.53-3.27, p<0.001$ ), pretreatment ambulatory status (non-ambulatory vs. ambulatory, $\mathrm{HR}=2.64,95 \% \mathrm{CI}: 1.82-3.83, p<0.001)$, KPS $(\leq 70$ vs. $>70, \mathrm{HR}=4.45,95 \% \mathrm{CI}: 2.01-9.85, p<0.001)$, ECOG (3-4 vs. $1-2, \mathrm{HR}=2.96,95 \% \mathrm{CI}: 2.02-4.35, p<0.001$ ), extraspinal bone metastasis (present vs. absent, $\mathrm{HR}=$ 2.04, 95\%CI: 1.13-3.68, $p=0.018$ ), time developing motor deficit (1-7 vs. $>7, \mathrm{HR}=1.57,95 \%$ CI: $1.30-1.88$, $p<0.001)$ and time from $\mathrm{PCa}$ diagnosis $(\mathrm{HR}=1.37$, 95\%CI: 1.17-1.59, $p<0.001$ ), while no significant prognostic effect on overall survival was found for age $(\mathrm{HR}=$ 1.18, 95\%CI: $0.88-1.59, p=0.269$ ), number of involved vertebrae (single vs. multiple, $\mathrm{HR}=0.95,95 \% \mathrm{CI}$ : $0.58-$ 


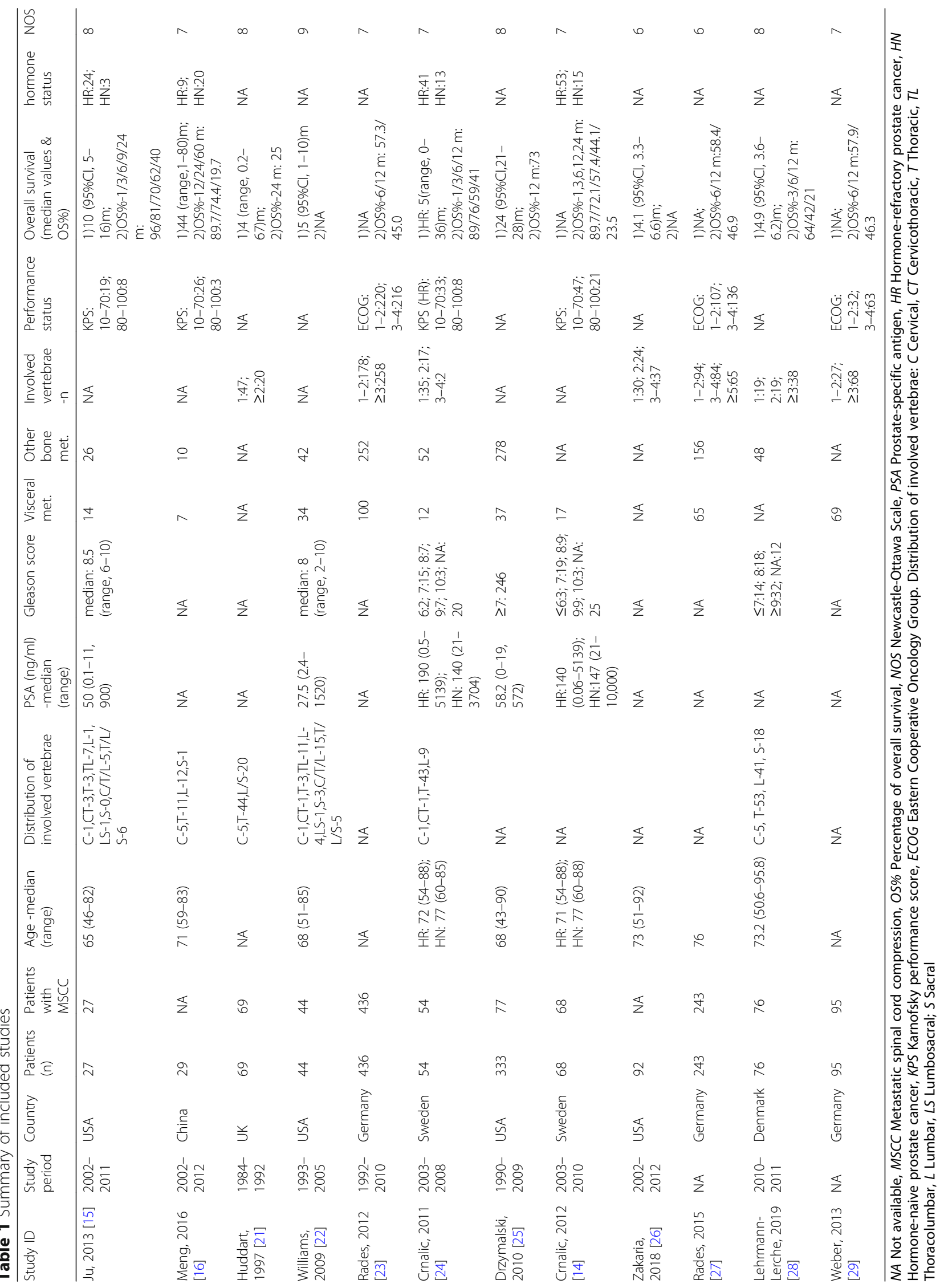



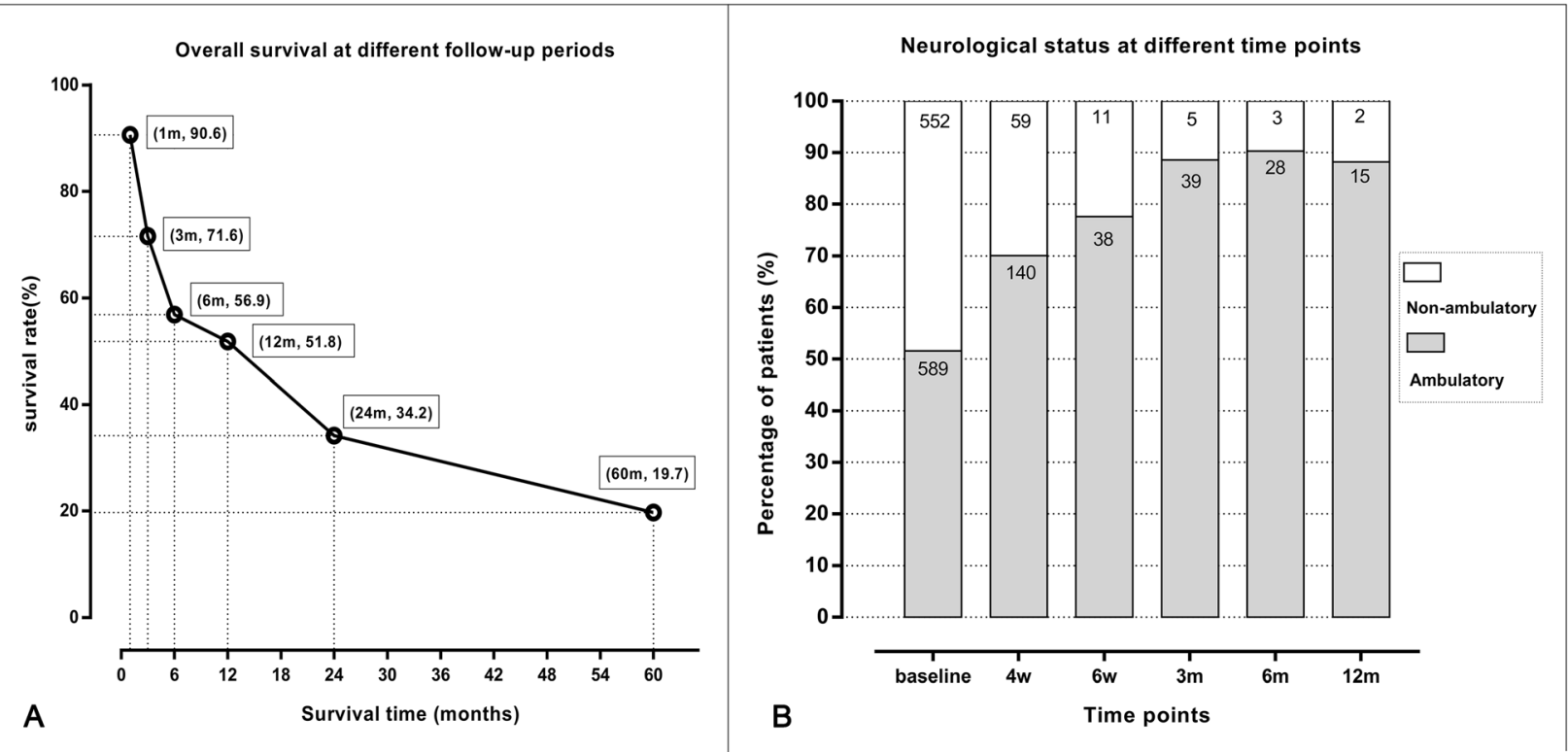

Fig. 2 The overall survival rates at different follow-up periods (a), and the percentages of ambulatory and non-ambulatory patients at different time points (b). Numbers of related patients at different time points were presented in the bars of the part B

$1.55, p=0.839 ;>2$ vs. $1-2, \mathrm{HR}=2.04,95 \% \mathrm{CI}: 0.81-5.18$, $p=0.130)$,PSA $(\mathrm{HR}=1.55,95 \% \mathrm{CI}: 0.88-2.76, p=0.129)$, and $\mathrm{BP}$ treatment $(\mathrm{HR}=0.47,95 \% \mathrm{CI}: 0.06-3.81, p=$ 0.480 ). Random-effect model was selected for the syntheses of visceral metastasis, ambulatory status, number of involved vertebrae, other bone metastasis, and BP treatment due to significant heterogeneity.

\section{Sensitivity analysis and publication bias test}

The results of sensitivity analysis and publication bias test for visceral metastasis and ambulatory status are available in Supplementary Fig. S1 and S2. No study was found to cause significant instability when it was omitted from the synthesis. No significant publication bias was found according to the methods of Egger's and Begg's tests.

\section{Discussion}

In this study, we systematically reviewed the prognostic factors of overall survival in patients with metastatic spinal disease from $\mathrm{PCa}$, and our quantitative metaanalyses demonstrated that presence of visceral metastasis, pre-treatment ambulatory status, KPS /ECOG, extraspinal bone metastasis, time developing motor deficit and time from $\mathrm{PCa}$ diagnosis were significant predictors for overall survival.

For guiding the treatment of spinal metastasis, many scoring systems have been established based on the significant prognostic factors [10-13]. Of these, the scoring systems of Tokuhashi [10] and Tomita [11] are the most commonly used tools for predicting overall survival. In these scores, however, various primary tumor types were included for developing the models, causing the low accuracy of prediction for some specific tumors due to that some special factors for different tumors were neglected, such as the PSA level, hormonotherapy and Gleason classification in spinal metastasis from PCa. Thus, several predicting scores have been developed for patients with metastatic spinal disease secondary to PCa $[14,23$, 27]. In the study of Crnalic et al. [14], 68 consecutive patients operated for MSCC were used for survival analysis and new score development. As a result, four predictors including hormone status, KPS, visceral metastasis and PSA were significantly associated with the overall survival and listed in the scoring system. Rades et al. [27] developed a survival score for the elderly PCa patients with spinal metastases based on a total of 243 patients, and the ambulatory status, visceral metastasis and time developing motor deficits were the significant characteristics in the final score. However, the treatment related factors such as target therapy, immunotherapy and hormonotherapy, which has obviously changed the patients' life expectancy, were seldom involved in these scores.

In our current systematic review and meta-analysis, we re-analyzed the prognostic effects of factors involved in 12 primary studies and 1566 patients. Among the identified significant factors, presence of visceral metastasis has been commonly accepted in most of the previous studies since that visceral metastasis may make the patients too deteriorated to tolerate some more invasive 


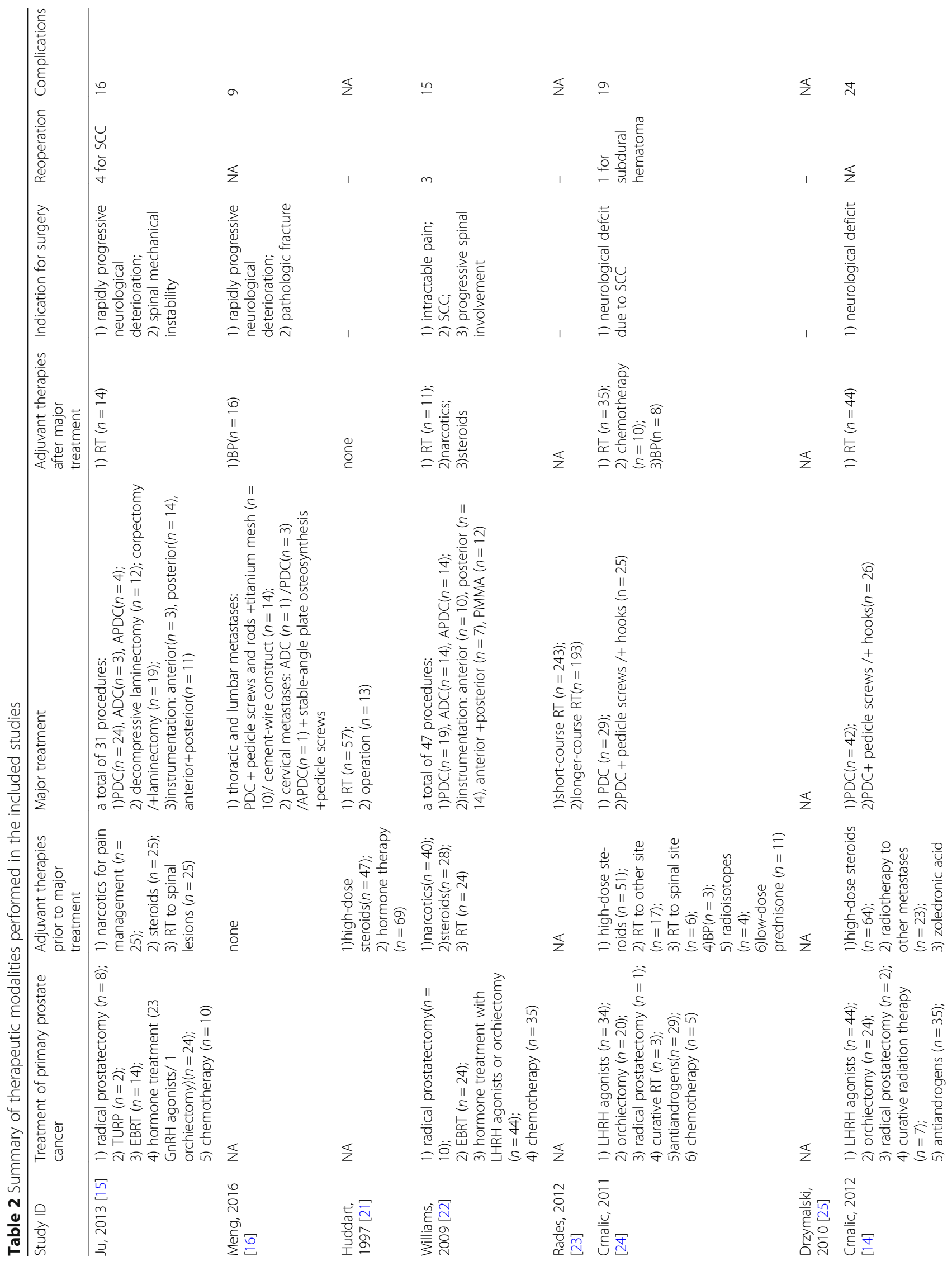




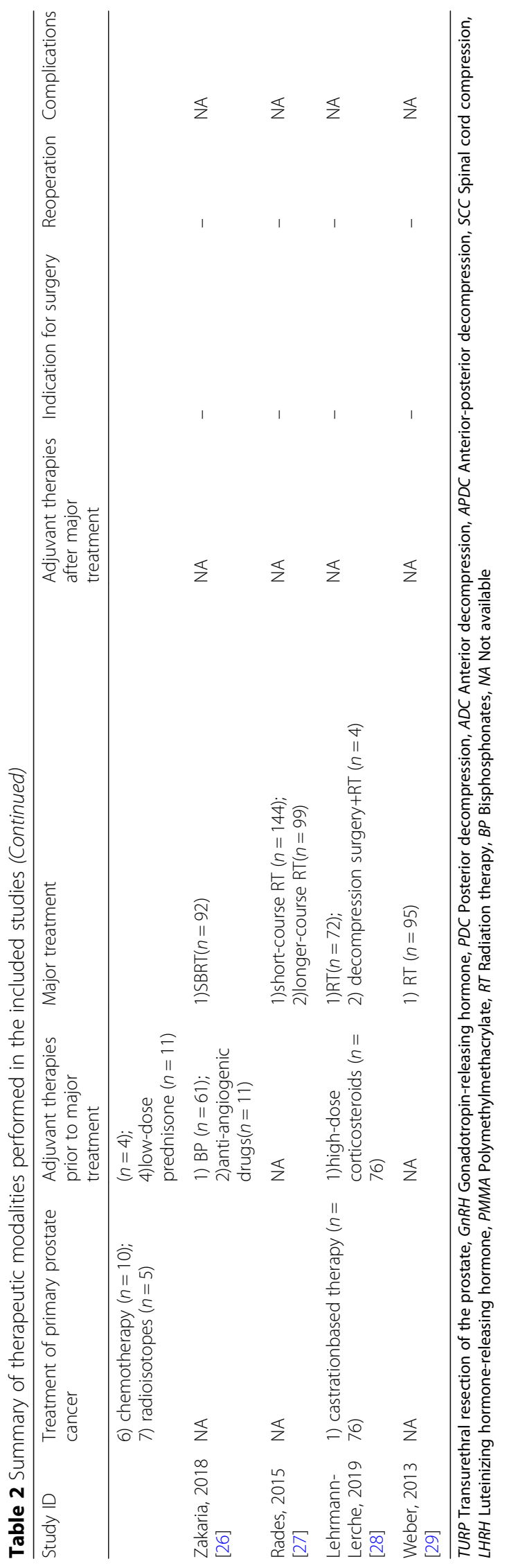




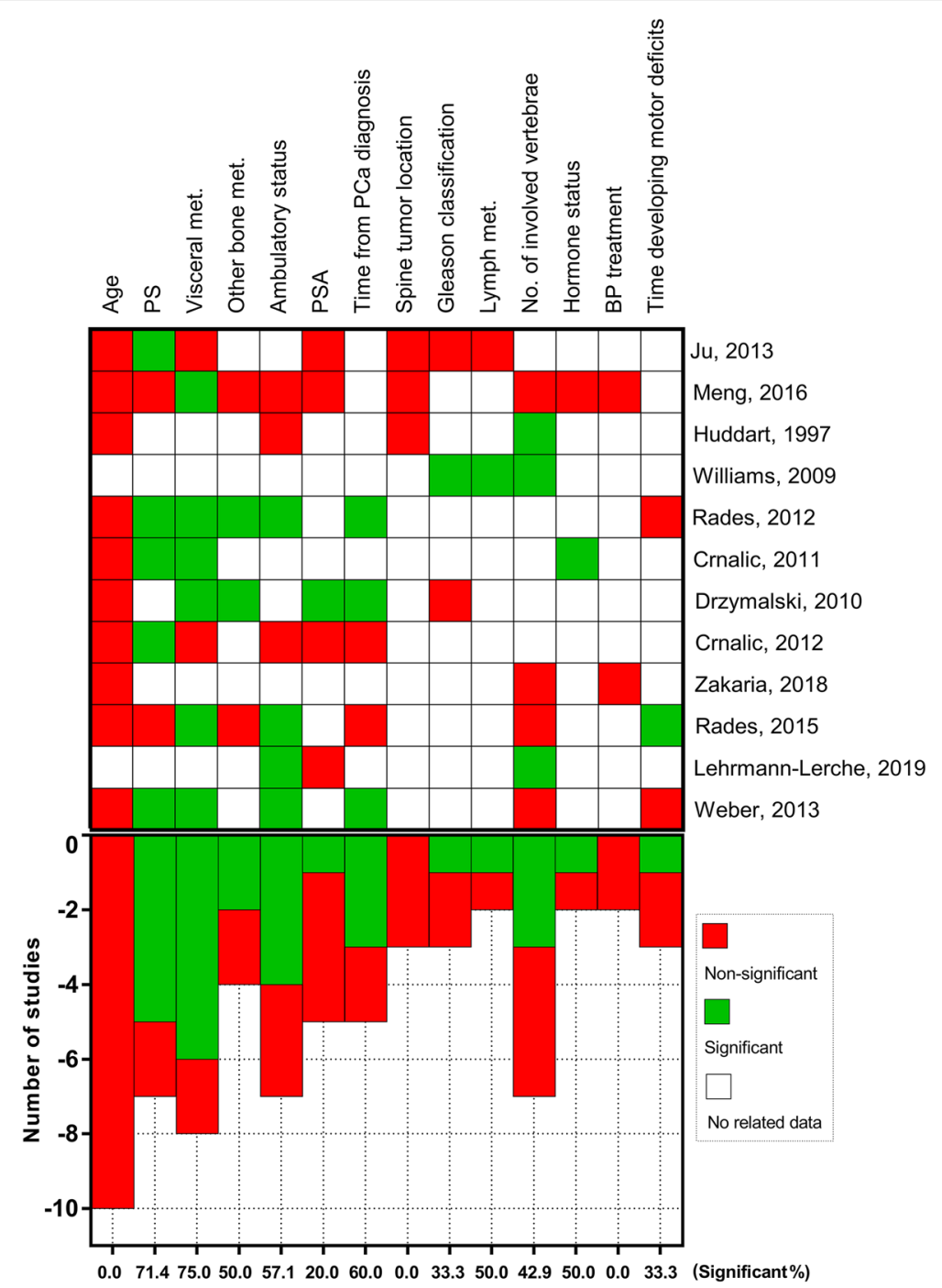

Fig. 3 A plot depicting the significance of the available prognostic factors for predicting overall survival of patients with spinal metastasis from PCa. Generally, the overall survival was significantly associated with performance status, visceral metastasis, ambulatory status and time from PCa diagnosis in more than half of the available studies

and curative therapies $[10-12,30]$. Being similar to the effect of co-exist of visceral metastasis, presence of extraspinal metastasis represents a diffused status of the tumor and an increased tumor burden to patients [10, 11, 30]. Thus, extraspinal bone metastasis was accepted as a significant factor in many scoring systems like the Enkaoua [30], Tokuhashi [10] and Tomita [11], which was accordant with the result of the current study.

The neurological status is a relatively contradictory factor in predicting patients' survival. It was not included as a prognostic factor in the scoring systems of Crnalic [14], Bauer [13], Bartels [31] and Tomita [11]. They believed that even in patients with neurological dysfunction, individualized treatment, such as decompression surgery, can greatly improve the neurological function of patients, thereby obtaining a relatively long survival period. Van der Linden et al. [12] also demonstrated that neurological status has no significant influence on the overall survival and they speculated that spinal cord paralysis could only reflect the anatomical location or size of spinal metastases. However, pre-treatment neurological status was included in the scoring systems of Tokuhashi [10], Sioutos [32], and Enkaoua [30]. In general, they speculated that patients with walking dysfunction due to MSCC are more prone to suffer from some fatal complications, such as pneumonia (especially in cancer patients with immunosuppression) [33]. In our study, we also found a 2.64-fold increase on the modality rate in non-ambulatory patients when compared to the ambulatory patients.

Performance status, mainly including KPS and ECOG, is used to assess the patient's overall health and 


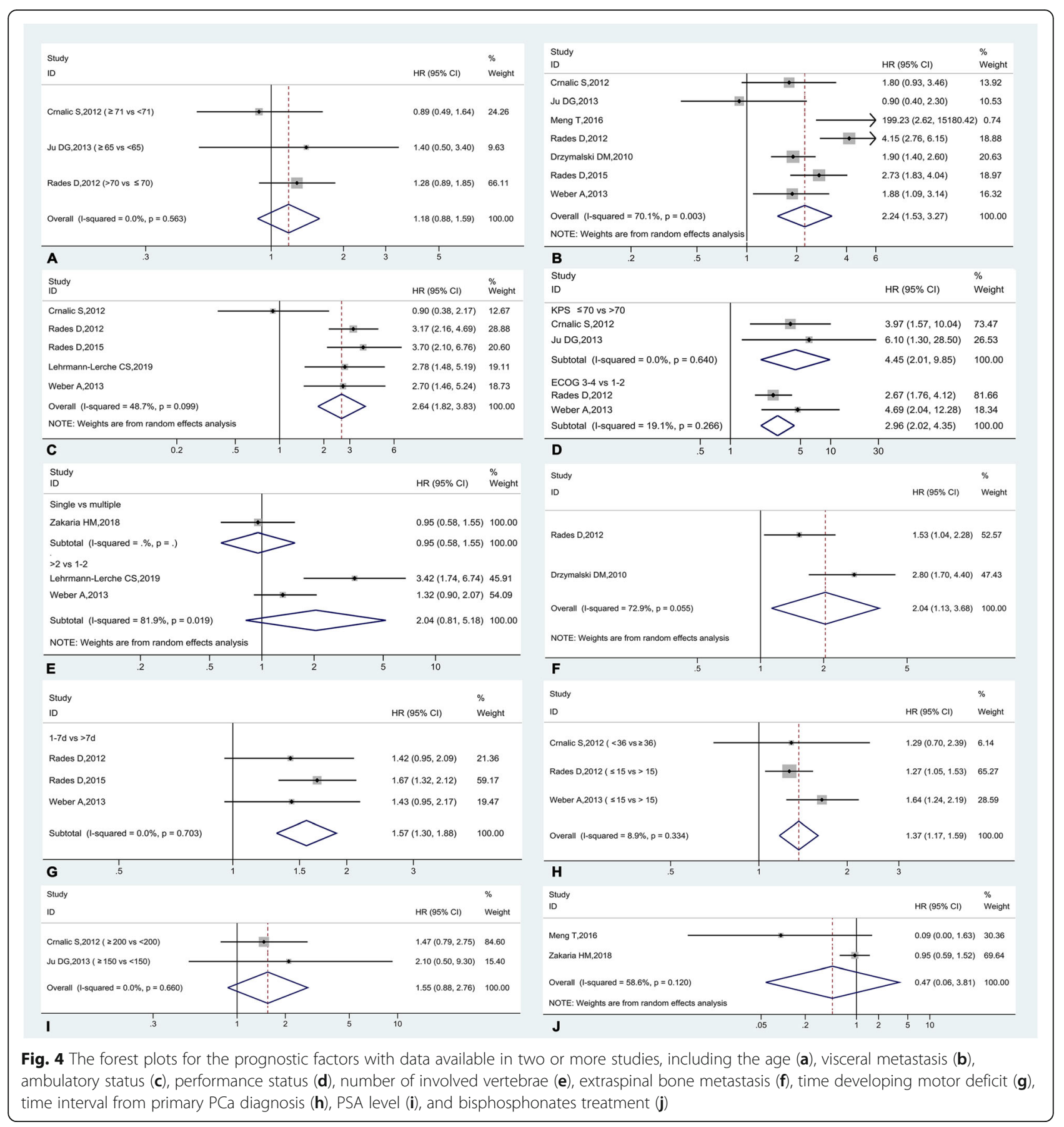

functional status. Patients with better performance status could better tolerate the side effects of some invasive anti-tumor treatments. In the study of Crnalic et al. [14], patients with KPS of less than 80 showed a 3.97 -fold increase on the overall risk of modality than those with KPS of $80-100$, and the KPS was included as a significant predictor in the score. The significant prognostic effects of the time developing motor deficit and time interval from primary $\mathrm{PCa}$ diagnosis are also in accordance with other previous studies.
The PSA level, as a PCa-specific factor which could partly reflect the degree of tumor progress, was analyzed in five studies [14-16, 25, 28] but only significant in one study [25]. In the study of Crnalic et al. [14], multivariate analysis showed that serum PSA concentration had no statistically significant effect on overall survival in patients with prostate spinal metastases. Despite this, PSA level was still included in their scoring system as they believed that higher serum PSA concentrations can reflect the advanced state of PCa. BP treatment, which was 
commonly used as a adjuvant therapy to inhibit the bony destruction, was also proven to be non-significant on the influence to overall survival.

In order to guide the incorporation of multi-disciplinary treatment for spinal metastatic tumors, the neurologic, oncologic, mechanical, and systemic (NOMS) framework was proposed by Laufer et al. [34], emphasizing the neurologic, oncologic, mechanical stability and systematic considerations. It is crucial to consider the patients' ability to tolerate the treatment procedures based on the systematic status or overall survival, which could be easily assessed through pretreatment characteristics. Thus, all of the potential predictors associated with overall survival reviewed and analyzed in this study should be take into consideration when selecting a treatment modality for spinal metastasis secondary to PCa.

\section{Limitation}

This study, nevertheless, has some limitations. Firstly, the primary studies included were all retrospective cohort studies, which may associated with inherent risk of bias in the data collection. Then, most of the studies were focused on assessing the prognostic effects of patients' characteristics, but the treatments applied were different among the studies, which may have influence to the overall survival. Finally, several factors were only analyzed in one of the studies, and the quantitative syntheses for these factors were not applicable. Thus, some more primary cohort studies may be needed to further identify the prognostic effects of these factors.

\section{Conclusions}

This study identified all available prognostic factors for spinal metastasis secondary to PCa based on published cohort studies. According to the results of meta-analyses, presence of visceral metastasis, ambulatory status, extraspinal bone metastasis, performance status, time developing motor deficit and time interval from primary tumor diagnosis were demonstrated to be significantly associated with the overall survival. When selecting the treatment modality for patients with spinal metastasis from $\mathrm{PCa}$, the clinicians should fully consider the patients' systematic status based on all associated prognostic factors.

\section{Supplementary information}

Supplementary information accompanies this paper at https://doi.org/10 1186/s12891-020-03412-0.

Additional file 1 Supplementary Figure S1. Results of sensitivity analysis for visceral metastasis (A) and ambulatory status (B). No study was found to cause significant instability when it was omitted from the synthesis.

Additional file $\mathbf{2}$ Supplementary Figure S2. Results of publication bias test for visceral metastasis (A\&B) and ambulatory status (C\&D). No significant publication bias was found according to the methods of Egger's $(p>0.100)$ and Begg's tests $(p>0.050)$.

\section{Abbreviations}

PCa: Prostate cancer; HR: Hazard ratio; KPS: Karnofsky performance score; ECOG: Eastern Cooperative Oncology Group; 95\%Cl: 95\% confidence interval; MSCC: Metastatic spinal cord compression; PSA: Prostate-specific antigen; NOS: Newcastle-Ottawa Scale; BP: Bisphophonates; RT: Radiation therapy

\section{Acknowledgments}

Not applicable

\section{Authors' contributions}

GZY: methodology, validation, formal analysis, investigation, data curation, writing-original draft, writing-reviewing and editing, project administration. ZT \& ZH: investigation, writing-reviewing and editing. PCG: conceptualization, methodology and validation. JWX: conceptualization, methodology, validation, investigation, writing-reviewing and editing. All authors read and approved the final manuscript.

\section{Funding}

This research did not receive any specific grant from funding agencies in the public, commercial, or not-for-profit sectors.

\section{Availability of data and materials}

The authors declare that all the data supporting the findings of this study are available within the article and its supplementary information files.

Ethics approval and consent to participate

Not applicable.

\section{Consent for publication}

Not applicable.

\section{Competing interests}

The authors declare that they have no competing interests.

\section{Author details}

${ }^{1}$ Department of Orthopedic Surgery, Tianjin First Central Hospital, 24 Fukang Rd, Nankai District, Tianjin 300192, China. ${ }^{2}$ Graduate School, Tianjin Medical University, Tianjin 300070, China.

Received: 2 March 2020 Accepted: 8 June 2020

Published online: 17 June 2020

\section{References}

1. Jemal A, Bray F, Center MM, Ferlay J, Ward E, Forman D. Global cancer statistics. CA Cancer J Clin. 2011;61(2):69-90.

2. Bubendorf $L$, Schöpfer A, Wagner U, Sauter G, Moch $H$, Willi N, et al. Metastatic patterns of prostate cancer: an autopsy study of 1,589 patients. Hum Pathol. 2000:31(5):578-83.

3. Mehra R, Kumar-Sinha C, Shankar S, Lonigro RJ, Jing X, Philips NE, et al. Characterization of bone metastases from rapid autopsies of prostate cancer patients. Clin Cancer Res. 2011;17(12):3924-32.

4. Gokaslan ZL. Spine surgery for cancer. Curr Opin Oncol. 1996;8:178-81.

5. Mercadante S. Malignant bone pain: pathophysiology and treatment. Pain. 1997:69:1-18.

6. Higano CS. To treat or not to treat, that is the question: the role of bonetargeted therapy in metastatic prostate cancer. J Clin Oncol. 2014;32: 1107-11.

7. Zhang D, Yin H, Wu Z, Yang X, Liu T, Xiao J. Surgery and survival outcomes of 22 patients with epidural spinal cord compression caused by thyroid tumor spinal metastases. Eur Spine J. 2013;22:569-76.

8. Sciubba DM, Petteys RJ, Dekutoski MB, Fisher CG, Fehlings MG, Ondra SL, et al. Diagnosis and management of metastatic spine disease. A review. J Neurosurg Spine. 2010;13(1):94-108.

9. Gabriel K, Schiff D. Metastatic spinal cord compression by solid tumors. Semin Neurol. 2004;24(4):375-83.

10. Tokuhashi $Y$, Matsuzaki H, Oda H, Oshima M, Ryu J. A revised scoring system for preoperative evaluation of metastatic spine tumor prognosis. Spine. 2005:30:2186-91.

11. Tomita K, Kawahara N, Kobayashi T, Yoshida A, Murakami H, Akamaru T. Surgical strategy for spinal metastases. Spine (Phila Pa 1976). 2001;26(3):298306. 
12. van der Linden YM, Dijkstra SP, Vonk EJ, Marijnen CA, Leer JW, Dutch bone metastasis study group. Prediction of survival in patients with metastases in the spinal column Results based on a randomized trial of radiotherapy. Cancer. 2005;103:320-8.

13. Bauer HC, Wedin R. Survival after surgery for spinal and extremity metastases. Prognostication in 241 patients. Acta Orthop Scand. 1995;66:143-6.

14. Crnalic S, Löfvenberg R, Bergh A, Widmark A, Hildingsson C. Predicting survival for surgery of metastatic spinal cord compression in prostate cancer: a new score. Spine (Phila Pa 1976). 2012;37(26):2168-76.

15. Ju DG, Zadnik PL, Groves ML, Hwang L, Kaloostian PE, Wolinksy JP, et al. Factors associated with improved outcomes following decompressive surgery for prostate cancer metastatic to the spine. Neurosurgery. 2013;73(4):657-66.

16. Meng T, Chen R, Zhong N, Fan T, Li B, Yin H, et al. Factors associated with improved survival following surgical treatment for metastatic prostate cancer in the spine: retrospective analysis of 29 patients in a single center. World J Surg Oncol. 2016;14(1):200.

17. Moher D, Liberati A, Tetzlaff J, Altman DG, PRISMA Group. Preferred reporting items for systematic reviews and meta-analyses: the PRISMA statement. BMJ. 2009;339:b2535.

18. Wells GA, Shea B, O'Connell D. Newcastle-Ottawa quality assessment scale cohort studies. 2012. http://uww.ohri.ca/programs/clinical_epidemiology/oxford.asp.

19. Higgins JP, Thompson SG, Deeks JJ, Altman DG. Measuring inconsistency in metaanalyses. BMJ. 2003;327:557-60.

20. Egger M, Davey Smith G, Schneider M, Minder C. Bias in meta-analysis detected by a simple, graphical test. BMJ. 1997:315:629-34.

21. Huddart RA, Rajan B, Law M, Meyer L, Dearnaley DP. Spinal cord compression in prostate cancer treatment outcome prognostic factors. Radiother Oncol. 1997;44(3):229-36.

22. Williams BJ, Fox BD, Sciubba DM, Suki D, Tu SM, Kuban D, et al. Surgical management of prostate cancer metastatic to the spine. J Neurosurg Spine. 2009;10(5):414-22.

23. Rades D, Douglas S, Veninga T, Bajrovic A, Stalpers LJ, Hoskin PJ, et al. A survival score for patients with metastatic spinal cord compression from prostate cancer. Strahlenther Onkol. 2012;188(9):802-6.

24. Crnalic S, Hildingsson C, Wikström P, Bergh A, Löfvenberg R, Widmark A. Outcome after surgery for metastatic spinal cord compression in 54 patients with prostate cancer. Acta Orthop. 2012;83(1):80-6.

25. Drzymalski DM, Oh WK, Werner L, Regan MM, Kantoff P, Tuli S. Predictors of survival inpatients with prostate cancer and spinal metastasis. Presented at the 2009 joint spine section meeting. Clinical article. J Neurosurg Spine. 2010;13(6):789-94.

26. Zakaria HM, Massie L, Basheer A, Elibe E, Boyce-Fappiano D, Shultz L, et al. Application of Morphometrics as a predictor for survival in patients with prostate Cancer metastasis to the spine. World Neurosurg. 2018;114:e913-9.

27. Rades D, Conde-Moreno AJ, Cacicedo J, Segedin B, Veninga T, Schild SE. Metastatic spinal cord compression a survival score particularly developed for elderly prostate Cancer patients. Anticancer Res. 2015;35(11):6189-92.

28. Lehrmann-Lerche CS, Thomsen FB, Røder MA, Suppli MH, Brasso K, Berg KD. Prognostic implication of gait function following treatment for spinal cord compression in men diagnosed with prostate cancer. Scand J Urol. 2019; 53(4):222-8

29. Weber A, Bartscht T, Karstens JH, Schild SE, Rades D. Survival in patients with metastatic spinal cord compression from prostate cancer is associated with the number of extra-spinal organs involved. Anticancer Res. 2013;33(10):4505-7.

30. Enkaoua EA, Doursounian L, Chatellier G, Mabesoone F, Aimard T, Saillant G. Vertebral metastases: a critical appreciation of the preoperative prognostic tokuhashi score in a series of 71 cases. Spine (Phila Pa 1976). 1997;22(19):2293-8.

31. Bartels RH, Feuth T, van der Maazen R, Verbeek AL, Kappelle AC, André Grotenhuis J, et al. Development of a model with which to predict the life expectancy of patients with spinal epidural metastasis. Cancer. 2007;110(9):2042-9.

32. Sioutos PJ, Arbit E, Meshulam CF, Galicich JH. Spinal metastases from solid tumors. Analysis of factors affecting survival. Cancer. 1995;76:1453-9.

33. Rades D, Fehlauer F, Schulte R, Veninga T, Stalpers LJ, Basic $H$, et al. Prognostic factors for local control and survival after radiotherapy of metastatic spinal cord compression. J Clin Oncol. 2006;24(21):3388-93.

34. Laufer I, Rubin DG, Lis E, Cox BW, Stubblefield MD, Yamada Y, et al. The NOMS framework: approach to the treatment of spinal metastatic tumors. Oncologist. 2013;18:744-51.

\section{Publisher's Note}

Springer Nature remains neutral with regard to jurisdictional claims in published maps and institutional affiliations.
Ready to submit your research? Choose BMC and benefit from:

- fast, convenient online submission

- thorough peer review by experienced researchers in your field

- rapid publication on acceptance

- support for research data, including large and complex data types

- gold Open Access which fosters wider collaboration and increased citations

- maximum visibility for your research: over $100 \mathrm{M}$ website views per year

At BMC, research is always in progress.

Learn more biomedcentral.com/submissions 